\title{
Advanced Statistical Analysis for Relationships between Particle Morphology (Size and Shape) and Shear (Static and Dynamic) Characteristics of Sands
}

\author{
Devapriya Chitral Wijeyesekera ${ }^{1}$, Alvin John Lim Meng Siang ${ }^{1}$, Ahmad Shukri Bin Yahaya ${ }^{2}$ \\ ${ }^{1}$ Department of Civil and Environmental Engineering, Universiti Tun Hussein Onn Malaysia, Batu Pahat, Malaysia \\ ${ }^{2}$ School of Civil Engineering, Universiti Sains Malaysia, Penang, Malaysia \\ Email: devapriya@uthm.edu.my, alvinjlms@gmail.com, shukri@eng.usm.my
}

Received October 28, 2013; revised November 25, 2013; accepted December 11, 2013

Copyright (C) 2013 Devapriya Chitral Wijeyesekera et al. This is an open access article distributed under the Creative Commons Attribution License, which permits unrestricted use, distribution, and reproduction in any medium, provided the original work is properly cited. In accordance of the Creative Commons Attribution License all Copyrights (C 2013 are reserved for SCIRP and the owner of the intellectual property Devapriya Chitral Wijeyesekera et al. All Copyright (C) 2013 are guarded by law and by SCIRP as a guardian.

\begin{abstract}
Morphology properties of naturally occurring sandy soil deposits are a consequence of the past geological transport history which gives rise to their different shape and size distributions. Five sand samples with different particle size and shape distributions were analysed statistically. Cluster analysis, performance indicators and probability distributions were used to find a representative shape parameter value. Static and dynamic tests were also contemporarily done to study the shear characteristics of the samples. Dimensionless relationships of the critical shear stress $\left(\tau_{\mathrm{cr}}\right)$ normalised with respect to the normal stress $\left(\sigma_{\mathrm{N}}\right)$ against the representative values are presented. Dynamic testing on the samples showed that the modulus reduction curve $\left(\mathrm{G} / \mathrm{G}_{\max }\right)$ and damping ratio (D) were also dependent on the morphology characteristics of the sand samples.
\end{abstract}

Keywords: Morphology; Sand; Statistics; Static and Dynamic Shear

\section{Introduction}

Soil mechanics/science is a prime academic discipline of civil engineering importance, particularly in foundation design and hazardous ground analysis. The mechanical behaviour of sand is highly dependent on the interparticle reaction and therefore classification based on the morphological aspects is deemed necessary. Soils differ from other engineering materials because of its morphology characteristics which require a distributed particulate mechanics approach. For sandy soils (assumed cohesionless), the interparticle reactions of sands rely heavily on its initial density, initial confining pressure and most importantly the interlocking structure of the particles. The friction angle $(\varnothing)$ is dependent on the relative density $\left(D_{r}\right)$ and it is correlated with a linear relationship $\varnothing=$ $\mathrm{AD}_{\mathrm{r}}+\mathrm{B}$, where A and $\mathrm{B}$ are constants [1].

Sand naturally occurs as granular material composed usually of broken rock fragments and mineral particles. The properties largely depend on the rocks from which they are derived. Different morphology (size and shapes) characteristics are imposed on the sand particles as a consequence of the prevailing geological transport mechanism such as fluvial, aeolian or glacial process [2]. Table 1 explains this further in indicating different particle shapes based on its genetic transport mechanisms.

The study of the significance of particle morphology on the response to its mechanical behaviour needs further research. BSCS, ASTM, and AASHTO classifications do not consider particle shapes in their respective soil classification systems. This has resulted in only very few established theories being based on the influence of particle shape or "combined size and shape" relationships on the static and dynamic loading behaviour of granular soils [3-6].

The key aim of this study was to assess thoroughly the classification of particle morphology using state of the art experimental and statistical analysis techniques. The findings were put into a wider context on how it can have a significant influence on the static and dynamic parameters in geotechnical design. 
Table 1. Description of the occurrence of particle shape based on its transportation mechanisms [2].

\begin{tabular}{lll}
\hline Type of shape & $\begin{array}{l}\text { Transport } \\
\text { Mechanism }\end{array}$ & Explanation \\
\hline Very spherical & High wind speeds & $\begin{array}{l}\text { Occur in sand dunes due to higher } \\
\text { wind speeds. } \\
\text { Blown by wind, because it is less } \\
\text { viscous than water it can collide } \\
\text { more energetically and violently } \\
\text { with each other. }\end{array}$ \\
Spherical & $\begin{array}{l}\text { Wind } \\
\text { (Aeolian) }\end{array}$ & $\begin{array}{l}\text { Lacks the necessary momentum } \\
\text { when colliding in water to produce } \\
\text { spherical particles. It is also due to } \\
\text { the water's cushioning effect. }\end{array}$ \\
Angular & $\begin{array}{l}\text { Water } \\
\text { (Fluvial) }\end{array}$ & $\begin{array}{l}\text { Grains deposited from ice are } \\
\text { normally more angular than those } \\
\text { in river deposits. }\end{array}$ \\
\hline $\begin{array}{l}\text { Very } \\
\text { angular }\end{array}$ & $\begin{array}{l}\text { Deposited from } \\
\text { ice (Glacial) }\end{array}$ &
\end{tabular}

\section{Design of Experiment, Materials and Testing Apparatus}

The design of experiment is important to carefully plan the type of materials used, the experiments required, and the amount of data needed for the study. The following paragraphs explain the design incorporated in this study.

Five types of sand samples were used to study the morphology characteristics of the sand particles. The first sample is the commercially available natural river sands from Kahang, Johor, Malaysia which were used as the primary material classed as well graded sand (SW). This was strategically chosen and subsequent alteration through riffling of the SW sand was adopted to obtain the second and third sample of uniformly graded ( $\left.\mathrm{SPu}_{\mathrm{Kahang}}\right)$ and gap graded (SPg) sands respectively which have different size distributions. The fourth sample is the windblown sands from Leighton Buzzard, UK ( $\left(\mathrm{SP}_{\mathrm{L} . \mathrm{Buzzard}}\right)$. It is documented as being uniformly graded sand and it has slightly rounded particle shapes. The fifth and last sample is the commercially manufactured glass beads available as "Glass Ballotini" were also used. These were also classed as uniformly graded but having near perfect rounded shapes.

The particle size distributions were analysed using the sieve analysis test as specified in BS 1377-2:1990. The shapes of the particles were observed and quantified using a digital microscope, shown in Figure 1(a), and where the magnified images of the sand particles are also given in Figure 1. A total of 100 randomly picked sand particles from each sample were analysed according to three established shape parameters suggested by Cho et al. [5], Goktepe and Sezer [4] and Tsomokos and Georgiannou [7]. The shape parameters are classified as sphericity (S), roundness $(R)$ and regularity $(\rho=[S+R] / 2)$.

Sphericity is defined as a function of diameter of the largest inscribed sphere relative to the diameter of the smallest circumscribed sphere. Roundness is quantified as the average of the inscribed diameter of circles that are

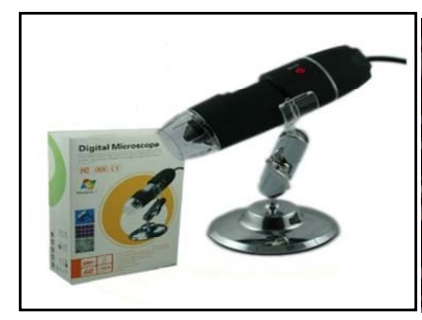

(a)

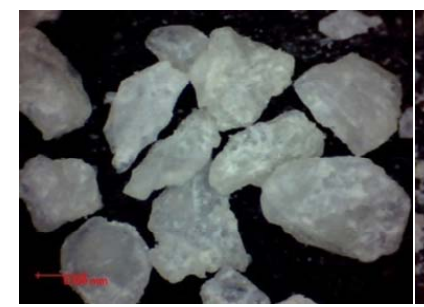

(c)

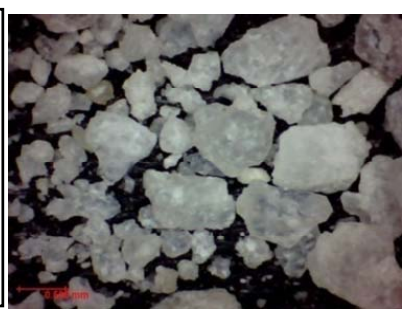

(b)

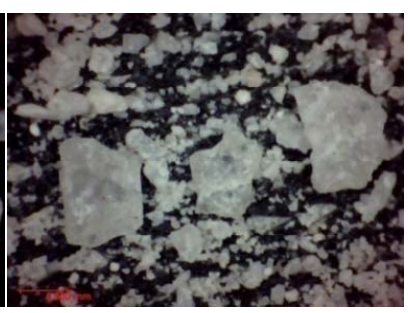

(d)

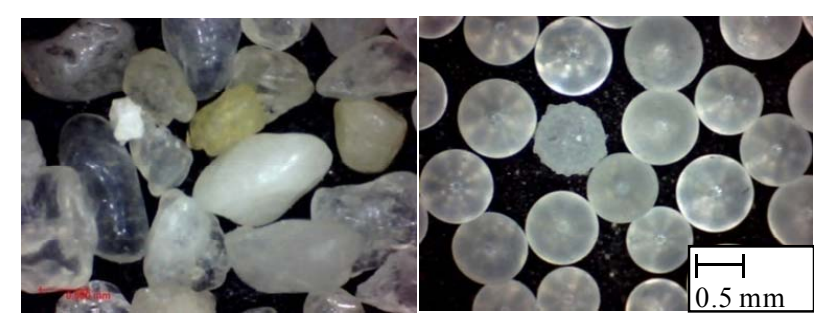

(e)

(f)

Figure 1. (a) The Digital microscope scanner. General view of the sand sample seen under the digital microscope for (b)

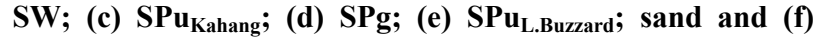
Glass Ballotini samples.

tangent to the edges of a particle over the diameter of the largest inscribed circle. Figure 2 shows the classification of the particle shapes based on a scale of these parametric values. Each particle was weighed to obtain the mass of individual particles. The manufactured Glass Ballotini was not analysed because it has perfectly spherical $(S \approx 1)$ and very round $(\mathrm{R} \approx 1)$ particles.

$\mathrm{X}$-ray Diffraction (XRD) and X-ray Fluorescence (XRF) studies showed that all the test samples were of similar mineralogy. This ensured that the test results were only dependent on the particle size and shape, so as to minimise the number of independent variables. Direct shear box tests were used to simulate static shear loading conditions on the sand samples. The dynamic characteristics were determined using cyclic testing with the GDS dynamic triaxial apparatus. To avoid repetition, the relevant choice of experiment in the design of experiments is outlined in Sections 5 and 6 for the static and dynamic test respectively.

\section{Particle Size and Shape Distribution Analysis}

The conventional size distribution grading parameters are 


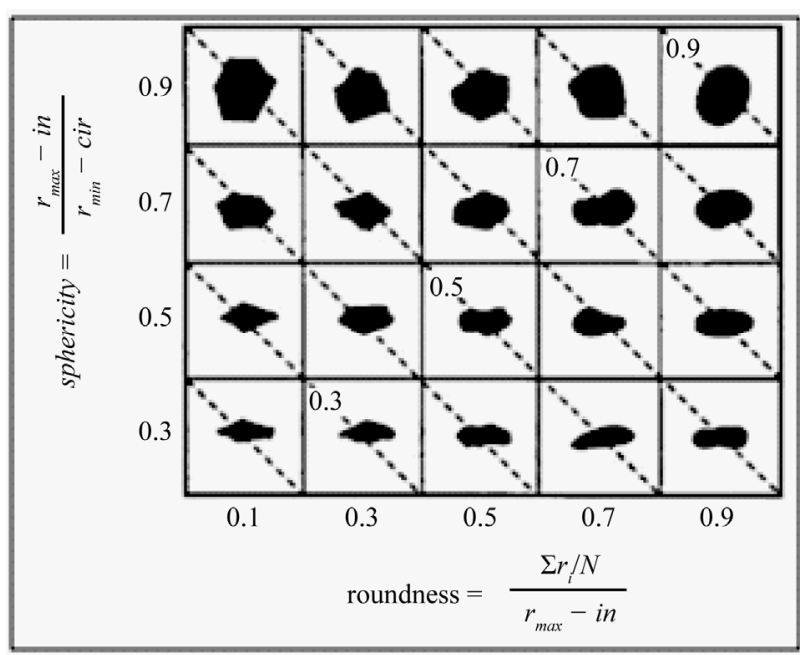

Figure 2. Particle shape determination (after [5]).

summarised in Table 2. Advanced analysis was done on the size distribution data and cumulative mass percentage frequency distributions were computed at quarter phi intervals. Graphic measures were adopted as explained by Singh and Chaudhri [8], to determine the various distribution parameters. Figure 3 shows the frequency curves by mass of two extreme distributions of SW and Glass Ballotini samples on a phi scale from the data.

Figure 3 further shows that the peak modes are different between the two samples, as the manufactured Glass Ballotini shows a highly concentrated peak value compared to that of the SW sample which has a wider distribution of particle sizes.

Further statistical analysis of the size distributions are summarised in Table 3, including the graphic mean, standard deviation, skewness and kurtosis of the data. It is seen that the mean values are in phi scale. The negative mean phi values found on the SW and Glass Ballotini samples show that the average size of these test particles is gravel like in nature. Other samples show an average particle size corresponding to coarse to very coarse sand.

All the samples except for the Glass Ballotini show positive skews. This explains that most of the size distribution lies to the left side of the mean on the phi scale. The SW sand shows very slight skewness $(-0.1 \leq \mathrm{s}<0.1)$ indicating an almost symmetrical distribution, as compared to the rest of the samples which has slight skewness $(0.1 \leq \mathrm{s}<0.6)$. The low negative skew $(-0.6 \leq \mathrm{s}<$ $-0.1)$ values for the Glass Ballotini show that there is a slight distribution which lies to the right side of the mean. The kurtosis shows the pattern of the height and sharpness of the peak of the distribution relative to the rest of the data measured. All the samples except for the Glass Ballotini gave moderate kurtosis values $(0.6 \leq \mathrm{k}<1)$, indicating a flatter peak near the mode of the distribution.
Table 2. Conventional particle grading properties.

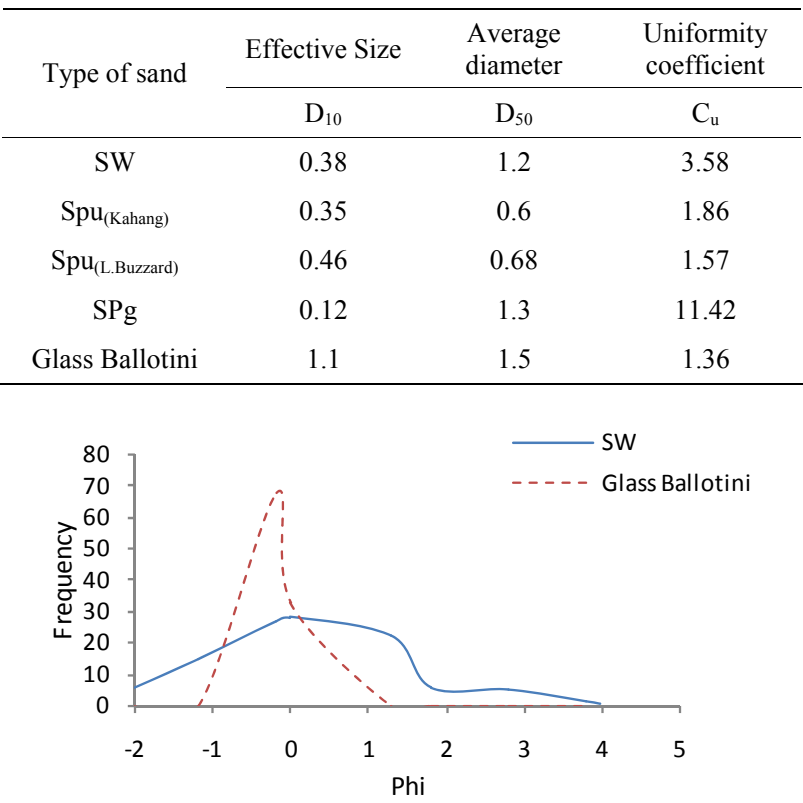

Figure 3. Frequency curves of SW and Glass Ballotini on the phi scale.

Table 3. Statistical analysis on the grading parameters.

\begin{tabular}{lcccc}
\hline Sample & $\begin{array}{c}\text { Graphic } \\
\text { Mean }\end{array}$ & $\begin{array}{c}\text { Std. } \\
\text { deviation }\end{array}$ & $\begin{array}{c}\text { Skewness } \\
(\mathrm{s})\end{array}$ & $\begin{array}{c}\text { Kurtosis } \\
(\mathrm{k})\end{array}$ \\
\hline $\mathrm{SW}$ & -0.15 & 1.181 & 0.037 & 0.653 \\
$\mathrm{SPg}$ & 0.607 & 1.609 & 0.614 & 0.609 \\
$\mathrm{SPu}_{(\text {Kahang })}$ & 0.817 & 0.532 & 0.341 & 0.973 \\
$\mathrm{SPu}_{(\mathrm{L} . \text { Buzzard }}$ & 0.6 & 0.342 & 0.351 & 0.820 \\
$\mathrm{Glass} \mathrm{Ballotini}$ & -0.487 & 0.302 & -0.107 & 1.723 \\
\hline
\end{tabular}

Strong kurtosis value $(\mathrm{k}>1)$ of the Glass Ballotini confirms a high peak on the distribution as seen in Figure 3.

Figure 4 illustrates the extreme roundness in the distributions for the $\mathrm{SW}$ and $\mathrm{SPu}_{(\mathrm{L} . \mathrm{Buzzard})}$ sand. The samples have distinctively different peak mode values. Table 4 gives the statistical analysis of the shape parameter data.

The sphericity (S) parameters for all the samples gave negative skew, indicating the size of the values lie to the right side of the mean. This shows that the majority of the particles have high sphericity values. The roundness $(R)$ and regularity $(\rho)$ parameter on the other hand showed positive skews. This indicates that most of the distribution lies to the left side of the mean.

The kurtosis for the S parameter shows that the SW and SPg sample have a strong kurtosis value $(\mathrm{k}>1)$, indicating a sharper peak on the distribution. The small negative kurtosis values found on the $\mathrm{SPu}_{(\mathrm{Kahang})}$ and $\mathrm{SPu}_{\text {(L.Buzzard) }}$ indicates a less distinct peak in the sphericity distribution $(-0.6 \leq \mathrm{k}<-0.1)$. For the $\mathrm{R}$ and $\rho$ parameters, the highest value in the kurtosis $(\mathrm{k}>1)$ is evident 


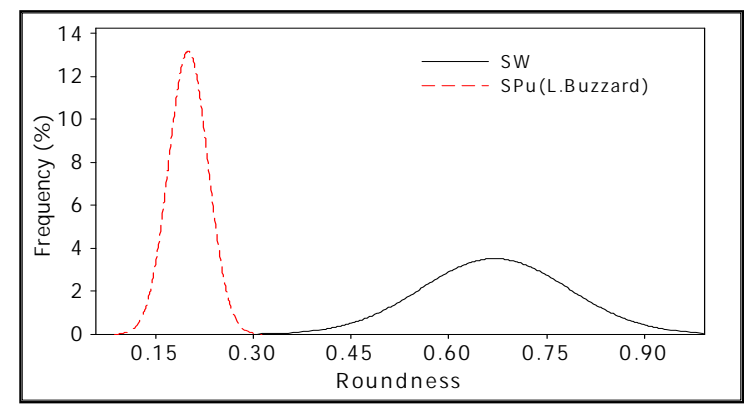

Figure 4. Frequency curves of $S W$ and $S P u_{(L . B u z z a r d)}$ on the roundness parameter.

Table 4. Statistical analysis on the shape parameters.

\begin{tabular}{|c|c|c|c|c|}
\hline \multirow{2}{*}{ Sample } & \multicolumn{4}{|c|}{ Sphericity (S) } \\
\hline & SW & SPg & $\mathrm{SPu}_{\text {(Kahang) }}$ & $\mathrm{SPu}_{\text {(L.Buzzard) }}$ \\
\hline Mean & 0.612 & 0.611 & 0.62 & 0.671 \\
\hline Std. deviation & 0.074 & 0.074 & 0.096 & 0.108 \\
\hline Skewness (s) & -0.01 & -0.031 & -0.317 & -0.270 \\
\hline Kurtosis (k) & 1.284 & 2.706 & -0.369 & -0.547 \\
\hline \multirow{2}{*}{ Sample } & \multicolumn{4}{|c|}{ Roundness (R) } \\
\hline & SW & SPg & $\mathrm{SPu}_{\text {(Kahang) }}$ & $\mathrm{SPu}_{(\text {L.Buzzard })}$ \\
\hline Mean & 0.2 & 0.242 & 0.342 & 0.674 \\
\hline Std. deviation & 0.03 & 0.076 & 0.099 & 0.106 \\
\hline Skewness (s) & 0.267 & 4.19 & 1.063 & 0.338 \\
\hline Kurtosis (k) & 1.509 & 24.29 & 2.225 & -0.039 \\
\hline \multirow{2}{*}{ Sample } & \multicolumn{4}{|c|}{ Regularity ( $\rho$ ) } \\
\hline & SW & SPg & $\mathrm{SPu}_{\text {(Kahang) }}$ & $\mathrm{SPu}_{(\mathrm{L} . \text { Buzzard })}$ \\
\hline Mean & 0.406 & 0.427 & 0.48 & 0.67 \\
\hline Std. deviation & 0.039 & 0.041 & 0.074 & 0.082 \\
\hline Skewness (s) & 1.306 & 0.382 & 0.249 & 0.341 \\
\hline Kurtosis (k) & 1.177 & 3.342 & 0.670 & -0.195 \\
\hline
\end{tabular}

in the SPg sample. This shows a very distinct peak on the $\mathrm{R}$ and $\rho$ distributions. The graphic mean and the moment mean were found to be similar as also observed by Singh and Chaudri [8] in their study.

\section{Advanced Analysis of Particle Shapes}

\subsection{Cluster Analysis}

Such a statistical study of particle shapes has not been done in the past. This study focussed on providing a better identification on the classification of the particle shapes. Previous researchers used only the average of the data to represent the shape parameters $[5,9,10]$. However, there is a possibility that such analysis will have some spatial discontinuities. In this study, statistical solutions of cluster analysis, performance indicators and probability distributions were used to find representative shape parameter values.
From the data collected, the k-means cluster analysis using the Minitab software was used to divide the data of the particle shape parameters and the mass into groups to examine similarities and dissimilarities in the characteristic data observed. k-means cluster analysis was used because of its suitability in catering a reasonably large amount of data and the ability to predetermine the number of clusters required [11]. Four clusters were used to separate the data which represented the extreme values of the particle shape and mass data. It can be seen from Table 5 that the data for each sample are divided into four groups of cluster each having its own centroid. The clusters represent the groups where it shows similarities in the data of the shape parameter and particle mass relationship. The cluster with the most number of data observations would be the most dominant group in the sample data.

\subsection{Performance Indicators}

Performance indicators (PI) were also used with the Matlab software to accurately judge which type of parent distribution (Normal, Weibull, Log-normal and Exponential) is the most appropriate to represent the shape parameters data. The performance indicators (PI) used in the research was as that suggested by Evans et al. [12] and Kottegoda and Rosso [13]. These consist of two measures that are error measures; mean absolute error (MAE), root mean squared error (RMSE), and the accuracy measures; coefficient of determination $\left(\mathrm{R}^{2}\right)$ and the prediction accuracy (PA). These performance evaluators measure how close the predicted modelled values are to the observed values [14,15]. For error measures, the smallest error will indicate the best distribution while for accuracy measures, values approaching 1 will indicate the best distribution. Table 6 shows the distribution of the shape parameters for all the samples. The appropriate distribution based on the performance indicators are shaded in grey.

\subsection{Probability Determination}

Once the best fit distributions were identified by performance indicators, the probability density function (PDF) of the fitted distribution was used to calculate the exceedence, or the probability values of the shape parameters which were equalled or have exceeded the range of the most dominant cluster. Table 7 shows the probability percentage of the extreme values of each cluster according to its shape parameters. The probability percentages indicate that the range of the extreme values of the most dominant cluster appears to have the highest percentage, indicating a high likelihood that this range of values would occur in a set of samples. Hence, the most dominant cluster centroid was used as a representative 
Table 5. Summary of the cluster analysis for all the samples of each shape parameter of sphericity (S), roundness (R) and regularity $(\rho)$.

\begin{tabular}{|c|c|c|c|c|c|c|c|c|c|c|c|c|}
\hline \multirow{3}{*}{$\begin{array}{c}\text { Cluster } \\
\text { No. }\end{array}$} & \multicolumn{3}{|c|}{ SW } & \multicolumn{3}{|c|}{ SPg } & \multicolumn{3}{|c|}{$\mathbf{S P u} \mathbf{u}_{\text {(Kahang) }}$} & \multicolumn{3}{|c|}{$\mathbf{S P} \mathbf{u}_{\text {(L.Buzzard) }}$} \\
\hline & \multirow{2}{*}{$\begin{array}{c}\text { No. of } \\
\text { particles }\end{array}$} & \multicolumn{2}{|c|}{ Cluster Centroid } & \multirow{2}{*}{$\begin{array}{c}\text { No. of } \\
\text { particles }\end{array}$} & \multicolumn{2}{|c|}{ Cluster Centroid } & \multirow{2}{*}{$\begin{array}{l}\text { No. of } \\
\text { particles }\end{array}$} & \multicolumn{2}{|c|}{ Cluster Centroid } & \multirow{2}{*}{$\begin{array}{c}\text { No. of } \\
\text { particles }\end{array}$} & \multicolumn{2}{|c|}{ Cluster Centroid } \\
\hline & & S & Mass (g) & & $\mathrm{S}$ & Mass (g) & & S & Mass (g) & & $\mathrm{S}$ & Mass (g) \\
\hline 1 & 48 & 0.628 & 0.0067 & 6 & 0.563 & 0.0987 & 36 & 0.672 & 0.0011 & 26 & 0.572 & 0.0021 \\
\hline 2 & 13 & 0.742 & 0.01 & 18 & 0.723 & 0.0822 & 15 & 0.758 & 0.001 & 23 & 0.799 & 0.0016 \\
\hline 3 & 31 & 0.571 & 0.0062 & 65 & 0.607 & 0.0343 & 28 & 0.595 & 0.001 & 40 & 0.685 & 0.0015 \\
\hline 4 & 8 & 0.454 & 0.01 & 11 & 0.473 & 0.0394 & 21 & 0.487 & 0.001 & 11 & 0.456 & 0.0019 \\
\hline \multirow{2}{*}{$\begin{array}{c}\text { Cluster } \\
\text { No. }\end{array}$} & \multirow{2}{*}{$\begin{array}{c}\text { No. of } \\
\text { particles }\end{array}$} & \multicolumn{2}{|c|}{ Cluster Centroid } & \multirow{2}{*}{$\begin{array}{l}\text { No. of } \\
\text { particles }\end{array}$} & \multicolumn{2}{|c|}{ Cluster Centroid } & \multirow{2}{*}{$\begin{array}{l}\text { No. of } \\
\text { particles }\end{array}$} & \multicolumn{2}{|c|}{ Cluster Centroid } & \multirow{2}{*}{$\begin{array}{c}\text { No. of } \\
\text { particles }\end{array}$} & \multicolumn{2}{|c|}{ Cluster Centroid } \\
\hline & & $\mathrm{R}$ & Mass (g) & & $\mathrm{R}$ & Mass (g) & & $\mathrm{R}$ & Mass (g) & & $\mathrm{R}$ & Mass (g) \\
\hline 1 & 28 & 0.222 & 0.0058 & 12 & 0.189 & 0.123 & 35 & 0.386 & 0.0011 & 39 & 0.619 & 0.0018 \\
\hline 2 & 5 & 0.277 & 0.0073 & 2 & 0.672 & 0.031 & 7 & 0.562 & 0.001 & 7 & 0.912 & 0.0015 \\
\hline 3 & 51 & 0.195 & 0.0071 & 30 & 0.278 & 0.0438 & 42 & 0.303 & 0.001 & 38 & 0.746 & 0.0017 \\
\hline 4 & 16 & 0.153 & 0.0104 & 56 & 0.218 & 0.0337 & 16 & 0.218 & 0.0012 & 16 & 0.514 & 0.0018 \\
\hline \multirow{2}{*}{$\begin{array}{l}\text { Cluster } \\
\text { No. }\end{array}$} & \multirow{2}{*}{$\begin{array}{c}\text { No. of } \\
\text { particles }\end{array}$} & \multicolumn{2}{|c|}{ Cluster Centroid } & \multirow{2}{*}{$\begin{array}{c}\text { No. of } \\
\text { particles }\end{array}$} & \multicolumn{2}{|c|}{ Cluster Centroid } & \multirow{2}{*}{$\begin{array}{l}\text { No. of } \\
\text { particles }\end{array}$} & \multicolumn{2}{|c|}{ Cluster Centroid } & \multirow{2}{*}{$\begin{array}{c}\text { No. of } \\
\text { particles }\end{array}$} & \multicolumn{2}{|c|}{ Cluster Centroid } \\
\hline & & $\rho$ & Mass (g) & & $\rho$ & Mass (g) & & $\rho$ & Mass (g) & & $\rho$ & Mass $(\mathrm{g})$ \\
\hline 1 & 19 & 0.457 & 0.0091 & 8 & 0.433 & 0.1323 & 33 & 0.520 & 0.0011 & 33 & 0.640 & 0.0017 \\
\hline 2 & 1 & 0.537 & 0.0039 & 9 & 0.514 & 0.0708 & 10 & 0.600 & 0.001 & 8 & 0.843 & 0.0015 \\
\hline 3 & 69 & 0.402 & 0.0065 & 81 & 0.419 & 0.0361 & 51 & 0.446 & 0.001 & 35 & 0.723 & 0.0015 \\
\hline 4 & 11 & 0.330 & 0.0096 & 2 & 0.296 & 0.0575 & 6 & 0.353 & 0.0011 & 24 & 0.552 & 0.0021 \\
\hline
\end{tabular}

Table 6. The distributions of the shape parameters for all the samples based on the performance indicators.

\begin{tabular}{|c|c|c|c|c|c|c|c|c|c|c|c|c|c|}
\hline \multirow{2}{*}{ Sample } & \multirow{2}{*}{ Distribution } & \multicolumn{4}{|c|}{ Sphericity (S) } & \multicolumn{4}{|c|}{ Roundness (R) } & \multicolumn{4}{|c|}{ Regularity $(\rho)$} \\
\hline & & MAE & RMSE & $\mathrm{R}^{2}$ & PA & MAE & RMSE & $\mathrm{R}^{2}$ & PA & MAE & RMSE & $\mathrm{R}^{2}$ & PA \\
\hline \multirow{4}{*}{ SW } & Normal & 0.016 & 0.019 & 0.921 & 0.969 & 0.005 & 0.007 & 0.930 & 0.974 & 0.009 & 0.011 & 0.910 & 0.963 \\
\hline & Exponential & 0.388 & 0.502 & 0.803 & 0.905 & 0.123 & 0.159 & 0.833 & 0.922 & 0.265 & 0.343 & 0.772 & 0.887 \\
\hline & Weibull & 0.022 & 0.031 & 0.888 & 0.952 & 0.009 & 0.012 & 0.904 & 0.960 & 0.013 & 0.019 & 0.877 & 0.946 \\
\hline & Lognormal & 0.015 & 0.018 & 0.928 & 0.973 & 0.006 & 0.006 & 0.942 & 0.980 & 0.009 & 0.011 & 0.911 & 0.963 \\
\hline \multirow{4}{*}{$\mathrm{SPg}$} & Normal & 0.019 & 0.024 & 0.882 & 0.949 & 0.034 & 0.054 & 0.562 & 0.757 & 0.01 & 0.012 & 0.9 & 0.959 \\
\hline & Exponential & 0.39 & 0.504 & 0.767 & 0.885 & 0.133 & 0.163 & 0.747 & 0.873 & 0.278 & 0.359 & 0.836 & 0.923 \\
\hline & Weibull & 0.028 & 0.036 & 0.856 & 0.935 & 0.044 & 0.058 & 0.589 & 0.775 & 0.019 & 0.024 & 0.852 & 0.932 \\
\hline & Lognormal & 0.019 & 0.024 & 0.885 & 0.95 & 0.018 & 0.044 & 0.656 & 0.818 & 0.009 & 0.011 & 0.912 & 0.964 \\
\hline \multirow{4}{*}{$\mathrm{SPu}_{\text {(Kahang) }}$} & Normal & 0.009 & 0.014 & 0.961 & 0.99 & 0.017 & 0.029 & 0.884 & 0.95 & 0.006 & 0.012 & 0.95 & 0.985 \\
\hline & Exponential & 0.381 & 0.501 & 0.76 & 0.88 & 0.176 & 0.226 & 0.93 & 0.974 & 0.295 & 0.388 & 0.861 & 0.937 \\
\hline & Weibull & 0.008 & 0.02 & 0.945 & 0.982 & 0.023 & 0.032 & 0.892 & 0.954 & 0.014 & 0.024 & 0.908 & 0.963 \\
\hline & Lognormal & 0.014 & 0.018 & 0.951 & 0.985 & 0.009 & 0.015 & 0.953 & 0.986 & 0.005 & 0.008 & 0.967 & 0.993 \\
\hline \multirow{4}{*}{$\mathrm{SPu}_{(\mathrm{L} . \mathrm{Buzzard})}$} & Normal & 0.01 & 0.02 & 0.954 & 0.986 & 0.012 & 0.022 & 0.947 & 0.983 & 0.009 & 0.019 & 0.939 & 0.979 \\
\hline & Exponential & 0.388 & 0.515 & 0.764 & 0.883 & 0.394 & 0.518 & 0.880 & 0.948 & 0.408 & 0.535 & 0.879 & 0.947 \\
\hline & Weibull & 0.008 & 0.023 & 0.943 & 0.981 & 0.022 & 0.037 & 0.916 & 0.967 & 0.017 & 0.036 & 0.885 & 0.95 \\
\hline & Lognormal & 0.017 & 0.023 & 0.944 & 0.982 & 0.007 & 0.011 & 0.973 & 0.996 & 0.007 & 0.011 & 0.965 & 0.992 \\
\hline
\end{tabular}


Table 7. The probability percentage of the extreme values of each cluster according to its shape parameter.

\begin{tabular}{|c|c|c|c|c|c|c|c|c|}
\hline \multirow[b]{2}{*}{$\begin{array}{c}\text { Cluster } \\
\text { No }\end{array}$} & \multicolumn{2}{|c|}{ SW } & \multicolumn{2}{|c|}{ SPg } & \multicolumn{2}{|c|}{$\mathbf{S P \mathbf { u } _ { \text { (Kahang) } }}$} & \multicolumn{2}{|c|}{$\mathbf{S P} \mathbf{u}_{\text {(Kahang) }}$} \\
\hline & $\begin{array}{l}\text { Range of the } \\
\text { extreme values } \\
\text { of S }\end{array}$ & $\begin{array}{c}\text { Probability } \\
\text { percentage } \\
(\%)\end{array}$ & $\begin{array}{l}\text { Range of the } \\
\text { extreme values } \\
\text { of } \mathrm{S}\end{array}$ & $\begin{array}{c}\text { Probability } \\
\text { percentage } \\
(\%)\end{array}$ & $\begin{array}{l}\text { Range of the } \\
\text { extreme values } \\
\text { of } \mathrm{S}\end{array}$ & $\begin{array}{c}\text { Probability } \\
\text { percentage } \\
(\%)\end{array}$ & $\begin{array}{l}\text { Range of the } \\
\text { extreme values } \\
\text { of } \mathrm{S}\end{array}$ & $\begin{array}{l}\text { Probability } \\
\text { percentage }\end{array}$ \\
\hline 1 & $0.602-0.683$ & 40.6 & $0.545-0.602$ & 26.6 & $0.625-0.7$ & 33.5 & $0.523-0.623$ & 24.3 \\
\hline 2 & $0.7-0.838$ & 12.2 & $0.676-0.878$ & 18.9 & $0.718-0.806$ & 13.2 & $0.745-0.885$ & 22.3 \\
\hline 3 & $0.519-0.609$ & 35.5 & $0.569-0.659$ & 45.77 & $0.544-0.631$ & 29.1 & $0.63-0.730$ & 35.6 \\
\hline 4 & $0.417-0.5$ & 5 & $0.403-0.538$ & 15.9 & $0.427-0.531$ & 13.9 & $0.4-0.471$ & 2.6 \\
\hline $\begin{array}{l}\text { Cluster } \\
\text { No }\end{array}$ & $\begin{array}{l}\text { Range of the } \\
\text { extreme values } \\
\text { of } R\end{array}$ & $\begin{array}{l}\text { Probability } \\
\text { percentage }\end{array}$ & $\begin{array}{l}\text { Range of the } \\
\text { extreme values } \\
\text { of } R\end{array}$ & $\begin{array}{l}\text { Probability } \\
\text { percentage }\end{array}$ & $\begin{array}{l}\text { Range of the } \\
\text { extreme values } \\
\text { of } R\end{array}$ & $\begin{array}{l}\text { Probability } \\
\text { percentage }\end{array}$ & $\begin{array}{l}\text { Range of the } \\
\text { extreme values } \\
\text { of } R\end{array}$ & $\begin{array}{l}\text { Probability } \\
\text { percentage }\end{array}$ \\
\hline 1 & $0.209-0.245$ & 28 & $0.133-0.235$ & 49.7 & $0.337-0.462$ & 30.8 & $0.555-0.676$ & 41.8 \\
\hline 2 & $0.263-0.295$ & 2.8 & $0.595-0.750$ & 0 & $0.492-0.579$ & 15.1 & $0.683-0.829$ & 35.4 \\
\hline 3 & $0.174-0.207$ & 42.4 & $0.25-0.413$ & 38.4 & $0.256-0.329$ & 34.2 & $0.866-0.959$ & 3.6 \\
\hline 4 & $0.132-0.174$ & 19.6 & $0.131-0.238$ & 53.4 & $0.167-0.257$ & 19.2 & $0.411-0.555$ & 12.2 \\
\hline $\begin{array}{l}\text { Cluster } \\
\text { No }\end{array}$ & $\begin{array}{l}\text { Range of the } \\
\text { extreme values } \\
\text { of } \rho\end{array}$ & $\begin{array}{l}\text { Probability } \\
\text { percentage }\end{array}$ & $\begin{array}{l}\text { Range of the } \\
\text { extreme values } \\
\text { of } \rho\end{array}$ & $\begin{array}{l}\text { Probability } \\
\text { percentage }\end{array}$ & $\begin{array}{l}\text { Range of the } \\
\text { extreme values } \\
\text { of } R\end{array}$ & $\begin{array}{l}\text { Probability } \\
\text { percentage }\end{array}$ & $\begin{array}{l}\text { Range of the } \\
\text { extreme values } \\
\text { of } R\end{array}$ & $\begin{array}{l}\text { Probability } \\
\text { percentage }\end{array}$ \\
\hline 1 & $0.438-0.486$ & 18.6 & $0.361-0.467$ & 11.8 & $0.485-0.553$ & 28.4 & $0.605-0.678$ & 34.1 \\
\hline 2 & 0.537 & - & $0.480-0.574$ & 10.2 & $0.577-0.693$ & 9.4 & $0.804-0.891$ & 5.4 \\
\hline 3 & $0.367-0.427$ & 54.5 & $0.364-0.465$ & 77.0 & $0.402-0.484$ & 41.2 & $0.682-0.774$ & 31.7 \\
\hline 4 & $0.289-0.358$ & 10.8 & $0.284-0.309$ & 0 & $0.318-0.393$ & 10.5 & $0.478-0.594$ & 16.7 \\
\hline
\end{tabular}

value for the classification of the particle shape parameters. Table 8 summarises the centroids of the most dominant cluster for all the samples.

\section{Static Shear Characteristics}

The static shear behaviour of the sand samples was studied using the direct shear box apparatus. Three static normal stresses $\left(\sigma_{\mathrm{N}}\right)$ of 25,50 and $100 \mathrm{kPa}$ was imposed on all the samples to study the influence of particle morphology on the critical shear stress $\left(\tau_{\mathrm{cr}}\right)$. The shearing rate used was kept the same at $0.5 \mathrm{~mm} / \mathrm{min}$ for all the tests. Figure 5 shows the schematic diagram of the direct shear box test with annotations of the applied forces on the sample. Figure 6 illustrates the typical stress-strain relationship for all the samples where the critical stress occurs at large strains. Figure 7 shows the variation of the uniformity coefficient $\left(\mathrm{C}_{\mathrm{u}}\right)$ and the critical shear stress parameter $\left(\tau_{\mathrm{cr}} / \sigma_{\mathrm{N}}\right)$. A dimensionless relationship was obtained from analysing the critical shear stress $\left(\tau_{\mathrm{cr}}\right)$ normalised with respect to the normal stress $\left(\sigma_{\mathrm{N}}\right)$ against the uniformity coefficient $\left(\mathrm{C}_{\mathrm{u}}\right)$ for all the samples.

A trendline was obtained that is presented by a single polynomial relationship encompassing a series of different normal stresses. The $\mathrm{C}_{\mathrm{u}}$ and $\sigma_{\mathrm{N}}$ are known variables which is used to establish an independent variable which enables prediction of the critical shear stress $\left(\tau_{\mathrm{cr}}\right)$ of the soil. The best fit curve is represented by a polynomial trendline with a fairly exceptional coefficient of determination, $\mathrm{R}^{2}$ value and is as shown in the Equation (1).
Table 8. The representative values of the shape parameters based on the cluster analysis and probability distribution.

\begin{tabular}{cccc}
\hline \multirow{2}{*}{ Sample } & \multicolumn{3}{c}{ Dominant shape parameter cluster centroid } \\
\cline { 2 - 4 } & $\begin{array}{c}\text { Sphericity } \\
(\mathrm{S})\end{array}$ & $\begin{array}{c}\text { Roundness } \\
(\mathrm{R})\end{array}$ & $\begin{array}{c}\text { Regularity } \\
(\rho)\end{array}$ \\
\hline $\mathrm{SW}$ & 0.628 & 0.196 & 0.402 \\
$\mathrm{SPg}$ & 0.608 & 0.218 & 0.419 \\
$\mathrm{SPu}_{\text {(Kahang) }}$ & 0.673 & 0.303 & 0.447 \\
$\mathrm{SPu}_{\text {(L.Buzzard) }}$ & 0.685 & 0.619 & 0.723 \\
\hline
\end{tabular}

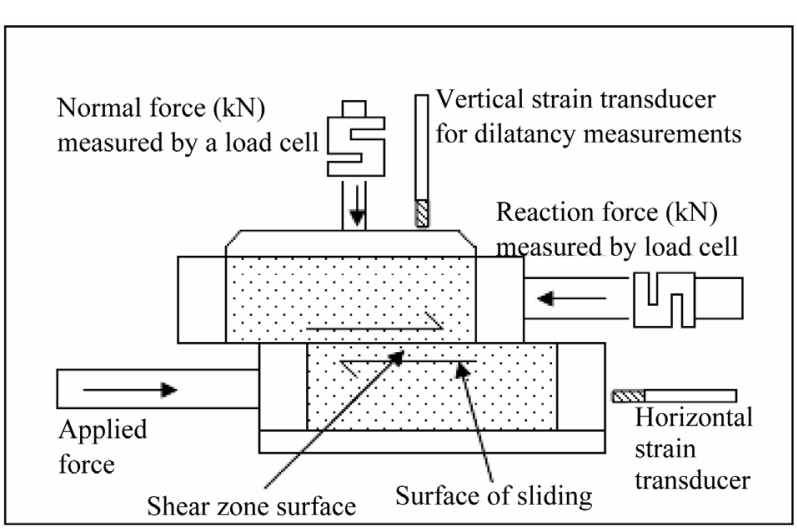

Figure 5. Schematic diagram of the direct shear box test.

$$
\begin{gathered}
\mathrm{T}_{\mathrm{cr}} / \sigma_{\mathrm{N}} \mathrm{vs} \mathrm{C}_{\mathrm{u}},\left(\mathrm{R}^{2}=0.793\right): \\
\frac{\tau_{\mathrm{cr}}}{\sigma_{\mathrm{N}}}=-0.011 \mathrm{C}_{\mathrm{u}}^{2}+0.170 \mathrm{C}_{\mathrm{u}}+0.437
\end{gathered}
$$




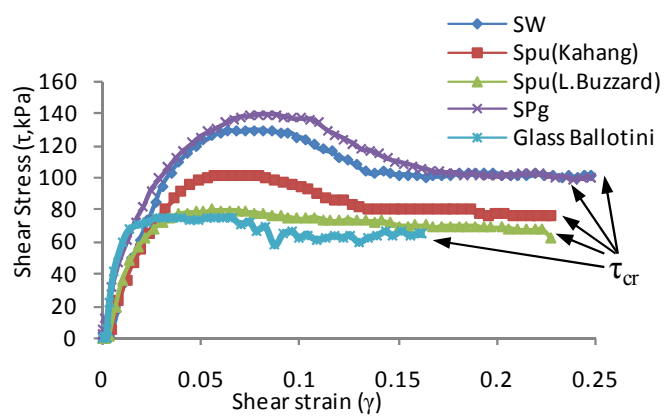

Figure 6. Stress-strain relationship from the direct shear box test for all the samples.

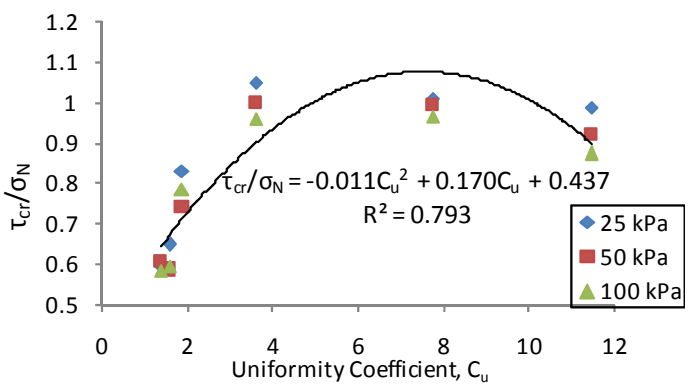

Figure 7. The relationship of the normalised shear stress $\left(\tau_{c r} / \sigma_{N}\right)$ against uniformity coefficient $\left(C_{u}\right)$.

Figure 8 shows the relationship of the effective diameter $\left(D_{10}\right)$ with the normalised critical shear stress $\left(\tau_{\mathrm{cr}} / \sigma_{\mathrm{N}}\right)$. The $\mathrm{D}_{10}$ relationship with $\tau_{\mathrm{cr}} / \sigma_{\mathrm{N}}$ is inversely proportional to the $C_{\mathrm{u}}$ versus the $\tau_{\mathrm{cr}} / \sigma_{\mathrm{N}}$ relationship where the decreasing values of $D_{10}$ would also decrease the strength of the soil. Again a curve was obtained that showed a polynomial relationship (Equation (2)).

$$
\begin{aligned}
& \tau_{\mathrm{cr}} / \sigma_{\mathrm{N}} \text { vs } \mathrm{D}_{10},\left(\mathrm{R}^{2}=0.556\right): \\
& \frac{\tau_{\mathrm{cr}}}{\sigma_{\mathrm{N}}}=-0.399 \mathrm{D}_{10}^{2}+0.170 \mathrm{D}_{10}+0.437
\end{aligned}
$$

The representative shape parameters from the cluster analysis were also studied for its relationships with the critical shear stress of the soil. It is seen in Figure 9 that the roundness $(\mathrm{R})$ parameter have better fitting relationships than the sphericity (S) parameter. However, the regularity $(\rho)$ parameter incorporating both the $S$ and $R$ parameter to an average value shows $R^{2}$ values that represent better relationships of the particle shapes and the critical shear strength. It seems that more spherical and rounder the particles are, the normalised shear stress would decrease to give a logarithmic trendline as presented in the set of equations below.

$$
\begin{aligned}
& \tau_{\mathrm{cr}} / \sigma_{\mathrm{N}} \text { vs } \mathrm{S},\left(\mathrm{R}^{2}=0.462\right): \\
& \frac{\tau_{\mathrm{cr}}}{\sigma_{\mathrm{N}}}=-0.60 \ln (\mathrm{S})+0.560 \\
& \tau_{\mathrm{cr}} / \sigma_{\mathrm{N}} \text { Vs } \mathrm{R},\left(\mathrm{R}^{2}=0.907\right):
\end{aligned}
$$

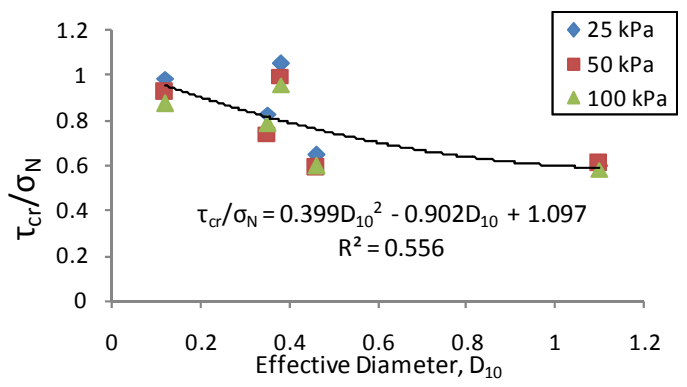

Figure 8. The relationship of the normalised shear stress $\left(\tau_{\mathrm{cr}} / \sigma_{\mathrm{N}}\right)$ against the effective diameter $\left(\mathrm{D}_{10}\right)$.
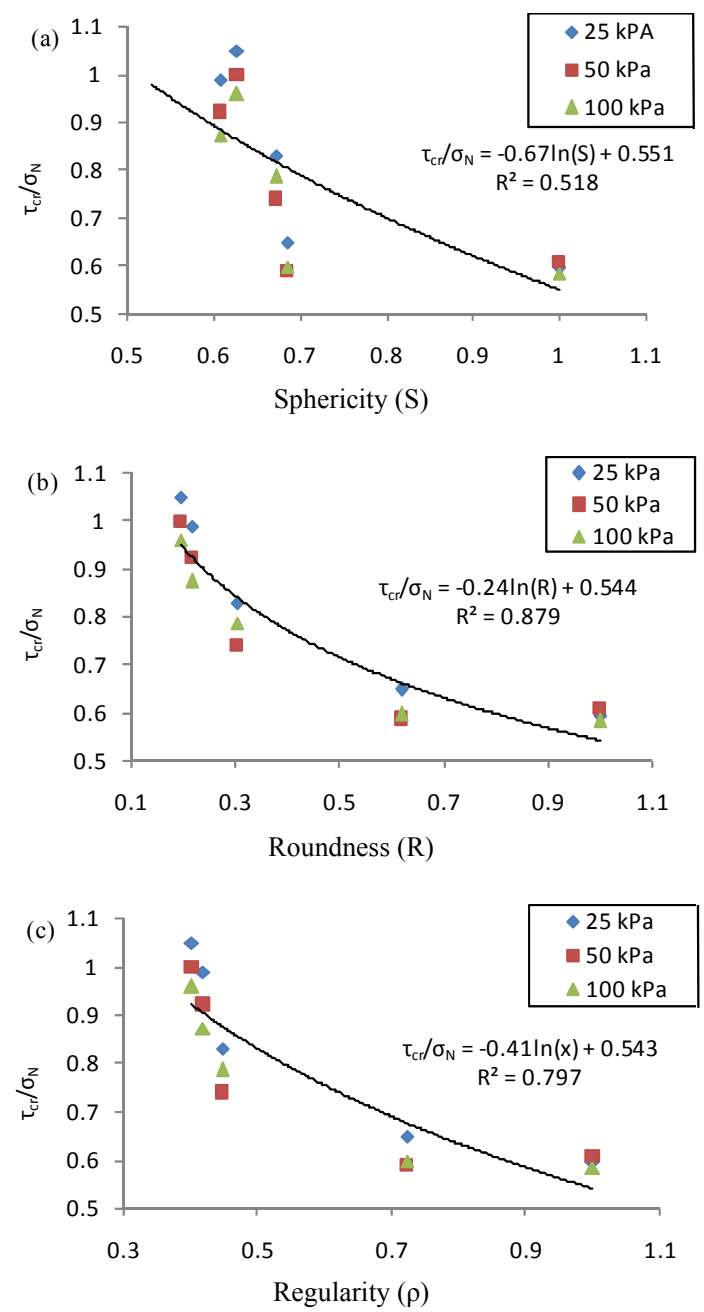

Figure 9. The relationship of the normalised shear stress $\left(\tau_{\mathrm{cr}} / \sigma_{\mathrm{N}}\right)$ against the (a) sphericity (S), (b) roundness $(\mathrm{R})$ and (c) regularity ( $\rho)$.

$$
\begin{aligned}
& \frac{\tau_{\text {cr }}}{\sigma_{\mathrm{N}}}=-0.24 \ln (\mathrm{R})+0.548 \\
& \tau_{\mathrm{cr}} / \sigma_{\mathrm{N}} \text { Vs } \rho,\left(\mathrm{R}^{2}=0.755\right): \\
& \frac{\tau_{\text {cr }}}{\sigma_{\mathrm{N}}}=-0.42 \ln (\rho)+0.529
\end{aligned}
$$


By studying the particle size and shape distribution parameters as well as the static stresses induced, relationships can be made to provide a significant understanding of predicting the critical shear strength behaviour of the soil.

\section{Dynamic Loading Mechanical Behavior}

Undrained cyclic triaxial tests on fully saturated samples were used to study the influence of particle morphology on the dynamic design parameters which is known as modulus reduction [16] or normalised modulus ratio $\left(\mathrm{G} / \mathrm{G}_{\max }\right)$ and damping ratio (D). Anisotropic consolidation was used to specifically simulate stress conditions of a soil under asymmetric loading and at shallow depths [17]. This process was done by initially applying an all around confining pressure of $100 \mathrm{kPa}$, followed by an initial static axial stress $\left(\sigma_{\mathrm{i}}\right)$ which was always kept at half of the monotonic strength/peak deviator stress $\left(\sigma_{\mathrm{p}}\right)$ of the sample $\left(\sigma_{\mathrm{i}}=0.5 \sigma_{\mathrm{p}}\right)$.

A cyclic loading frequency of $1.0 \mathrm{~Hz}$ and cyclic stress ratio (CSR) of 0.2 was used for the dynamic loading. The sand samples prepared were undercompacted as suggested by Ladd [18] and the size of the samples were 50 $\mathrm{mm}$ in diameter and $100 \mathrm{~mm}$ in length. Figure 10 shows the final set up of the tiraxial test apparatus where the cyclic loading was applied from the bottom of the sample.

The stress-strain behaviour observed in a typical cyclic triaxial test is represented by a hysteresis loop as shown in Figure 11. The hysteresis loop is an important feature which is used to determine important dynamic parameters such as the modulus reduction $\left(\mathrm{G} / \mathrm{G}_{\max }\right)$ and damping ratio (D). These parameters were determined as explained by Kramer [16]. Figure 12 shows the effect of the particle size distribution parameter of effective size $\left(D_{10}\right)$ on the modulus reduction curve $\left(G / G_{\max }\right)$.

It is seen that an increase in $\mathrm{D}_{10}$ would also show an

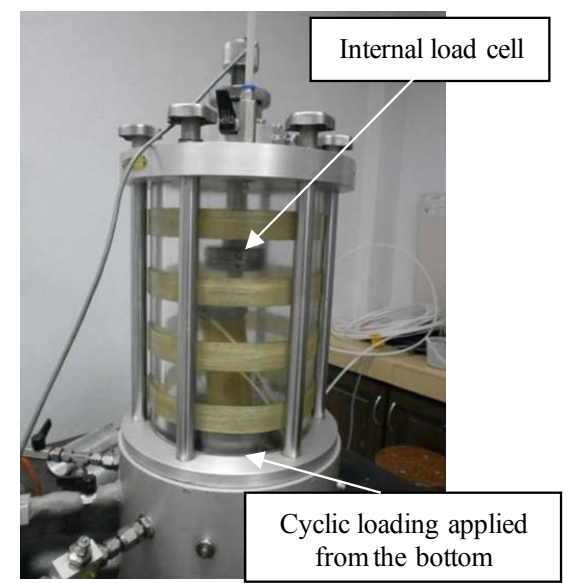

Figure 10. The dynamic triaxial test apparatus.

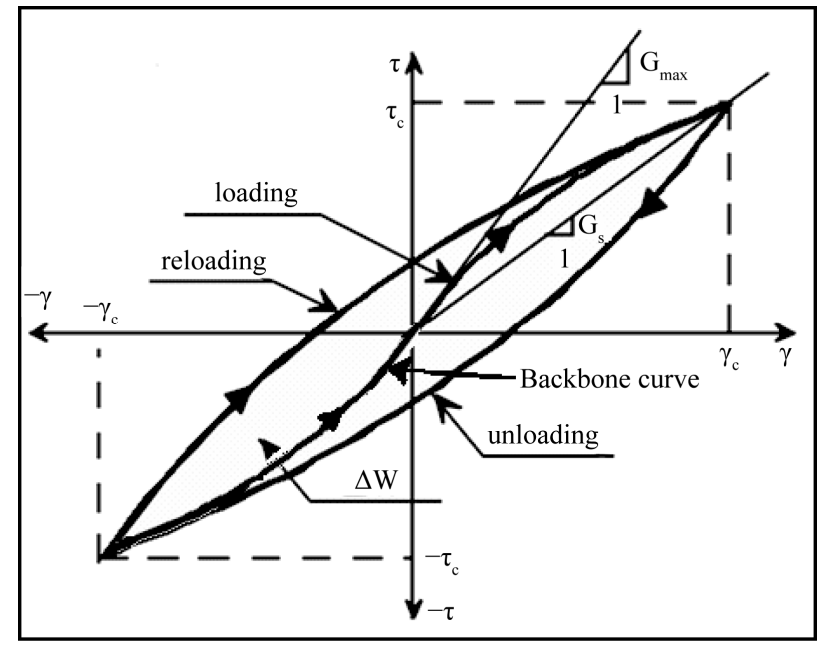

Figure 11. Typical stress-strain relation from a cyclic triaxial test.

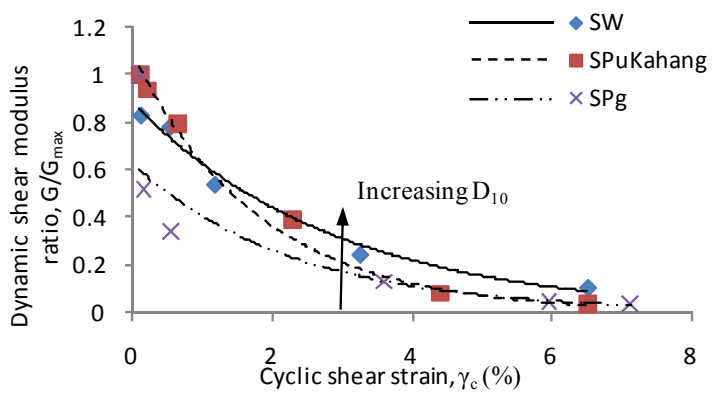

Figure 12. The behaviour of the dynamic modulus reduction curve with increasing effective size $\left(D_{10}\right)$.

increase in the modulus reduction curve. The shape parameters of sphericity (S), roundness $(\mathrm{R})$ and regularity ( $\rho$ ) was also seen to affect the modulus reduction curve as pointed out in Figure 13. The decrease in the shape parameters on the other hand increased the modulus reduction curve.

The energy dissipated in the samples during the cyclic test was quantified using the damping ratio (D). As was observed with the $\mathrm{G} / \mathrm{G}_{\max }$ behaviour, the morphology characteristics of the sand samples showed a considerable influence on the damping ratio (D). The results indicated that a decrease in the effective size $\left(D_{10}\right)$ resulted in an increase in the damping ratio (Figure 14). A decrease in the shape parameters (,$R$ and $\rho$ ) then showed an increased overall damping ratio (Figure 15).

The behaviour of the modulus reduction $\left(\mathrm{G} / \mathrm{G}_{\max }\right)$ curve was found to be dependent on the effective size $\left(D_{10}\right)$ and the change in the shape parameters of sphericity $(S)$, roundness $(R)$ and regularity $(\rho)$. Such variations were observed from past research by Vucetic and Dobry [19], Kramer [16], Okur and Ansal [20] to occur only on soils with high plasticity. However, despite the non existence of plasticity in the samples used in this 


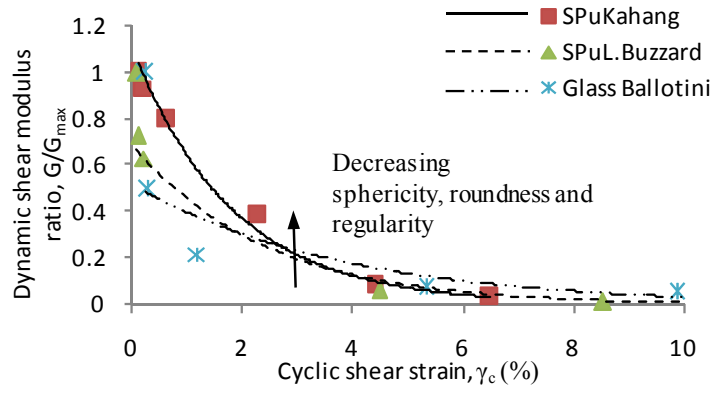

Figure 13. The behaviour of the dynamic modulus reduction curve with decreasing particle shape characteristics $(S$, $\mathbf{R}, \boldsymbol{\rho})$.

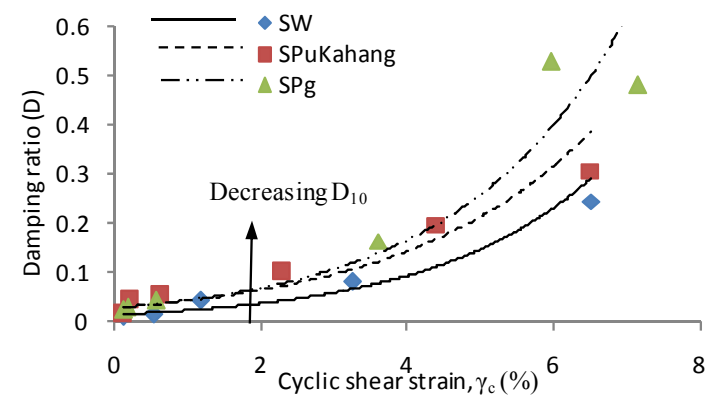

Figure 14. The relationships of the damping ratio (D) with increasing cyclic shear strain $\left(\gamma_{c}\right)$ and effective size $\left(D_{10}\right)$.

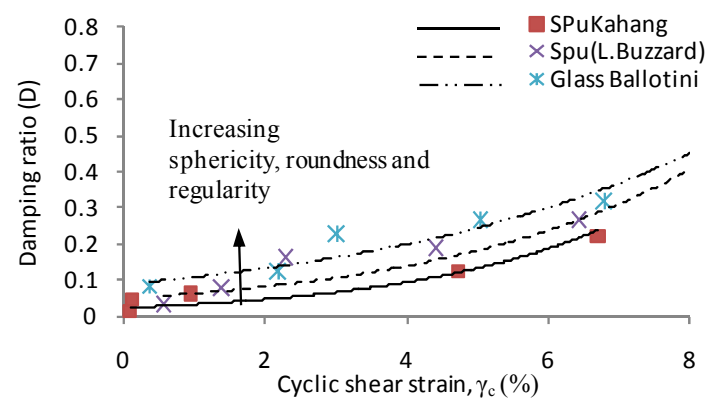

Figure 15. The relationships of the damping ratio (D) with increasing cyclic shear strain $\left(\gamma_{c}\right)$ and shape parameters $(S$, $\mathbf{R}, \boldsymbol{\rho})$.

research, there were still some variations in the dynamic shear modulus and modulus reduction curves indicating a high dependency on particle morphology.

\section{Conclusions}

The influence of particle morphology on the static and dynamic properties of sand was studied in this research. The importance of finding a representative shape parameter from the sand particles is required to have a better understanding on the mechanical properties of the soil based on the shapes of the particles.

In accordance with the statistical analysis done on the distributions of the particle size and shapes, the skewness of the particle size distribution showed that the sand sam- ples are coarse. The shape distribution based on the skewness showed that the majority of the sphericity parameter data for all samples were higher than the mean sphericity. However, the majority of the data on roundness and regularity parameters for all the samples were found to have lower values than the mean.

The cluster analysis was able to determine the most dominant values of the shape parameters of sphericity $(\mathrm{S})$, roundness $(R)$ and regularity $(\rho)$. The type of distribution of the shape parameter data was determined by performance indicators so that probability plots were able to search for the probability of the occurrence for the most dominant cluster. The analysis shows that there is a high percentage or a high likelihood that this range of shape parameter values is within the dominant cluster in a set of a sample. Hence, the most dominant cluster centroid was used as a representative value for the classification of the particle shape parameters.

The study also found that particle morphology has a significant influence on the static shear loading behaviour of the soil. The dimensionless relationships of the critical shear stress $\left(\tau_{\mathrm{cr}}\right)$ normalised with respect to the normal stress $\left(\sigma_{\mathrm{N}}\right)$ against the particle size and representative shape parameters of the sand samples were obtained. These relationships provided a significant understanding in predicting the critical shear strength behaviour of the soil by studying morphological characteristics of the soil as well as the static stress induced.

The dynamic loading characteristics of the sand samples have shown that the modulus reduction curve $\left(\mathrm{G} / \mathrm{G}_{\max }\right)$ and the damping ratio (D) were dependent on the effective size $\left(D_{10}\right)$ and also on the shape parameters of sphericity $(R)$, roundness $(R)$ and regularity $(\rho)$. However observations reported in the past studies [18-20], found this to only occur on soils with high plasticity. Despite the non-existence of plasticity in the samples tested in this research, notable variations still existed in the dynamic shear modulus and modulus reduction curves indicating a significant dependency on particle morphology.

\section{Acknowledgements}

The authors wish to record their sincere gratitude to UTHM staff for their constant support and guidance in this research.

\section{REFERENCES}

[1] A. J. M. S. Lim, "The Influence of Particle Morphology and Structure on the Static and Dynamic Characteristics of Sand," Ph.D. Manuscript (in preparation), 2013, University Tun Hussien Onn Malaysia.

[2] A.C. McLean and C. D. Gribble, "Geology for Civil Engineers," E \& FN Spon, an imprint of Chapman \& Hall, London, 1979, p. 45. 
[3] I. Cavarretta, "The Influence of Particle Characteristics on the Engineering Behaviour of Granular Materials," Ph.D. Dissertation, Imperial College London, London, 2009.

[4] A. B. Goktepe and A. Sezer, "Effect of Particle Shape on Density and Permeability of Sands," Proceedings of the Institution of Civil Engineers, Geotechnical Engineering, No. GE6, 2010, pp. 307-320.

[5] G. C. Cho, J. Dodds and J. C. Santamarina, "Particle Shape Effects on Packing Density, Stiffness and Strength: Natural and Crushed Sands," Journal of Geotechnical and Geoenvironmental Engineering, Vol. 132, No. 5, 2006, pp. 591-602.

http://dx.doi.org/10.1061/(ASCE)1090-0241(2006)132:5( $\underline{591)}$

[6] P. Gou and X. Su, "Shear Strength, Interparticle Locking and Dilatancy of Granular Materials," Canadian Geotechnical Journal, Vol. 44, 2006, pp. 570-591.

[7] A. Tsomokos and V. N. Georgiannou, "Effect of Grain Shape and Angularity on the Undrained Response of Fine Sands," Canadian Geotechnical Journal, Vol. 47, No. 5, 2009.

[8] M. Singh and A. R. Chaudri, "Size analysis of the Late Pliocene-Early Pleistocene Upper Siwalak Sediments, Northwestern Himalaya, India," International Journal of Geoscience, Vol. 4, No. 8, 2013, pp. 1120-1130. http://dx.doi.org/10.4236/ijg.2013.48106

[9] A. K. Alshibi and M. I. Alsaleh, "Characterizing Surface Roughness and Shape of Sands using Digital Microscopy," Journal of Computing in Civil Engineering, Vol. 18, No. 1, 2004, pp. 36-45. http://dx.doi.org/10.1061/(ASCE)0887-3801(2004)18:1(3 6)

[10] M. R. Brooke, "The Influence of Grain Shape on Dilatancy," Ph.D. Thesis, The University of Arizona, 2008.
[11] O. A. Abbas, "Comparisons Between Data Clustering Algorithms," The International Arab Journal of Information Technology, Vol. 5, No. 3, 2008, pp. 320-325.

[12] M. Evans, N. Hasting and B. Peacock, "Statistical Distributions," 3th Edition, Wiley, New York, 2000.

[13] N. T. Kottegoda and R. Rosso, "Statistic, Probability for Civil and Environmental Engineers," McGraw-Hill, Singapore, 1998.

[14] J. A. Rice, "Mathematical Statistics and Data Analysis, Third Addition," Cengage Learning, Belmont, Brooks/ Cole, 2007.

[15] D. H. Sanders, "Statistics, A First Course," 5th Edition, Mcgraw-Hill, Inc., Fort Worth, 1995.

[16] S. L. Kramer, "Geotechnical Earthquake Engineering," Prentice Hall, Upper Saddle River, 1996.

[17] M. T. Yilmaz, O. Pekcan and B. S. Bakir, "Undrained Cyclic Shear and Deformation Behaviour of Silt-Clay Mixtures of Adapazari, Turkey," Soil Dynamic and Earthquake Engineering, Vol. 24, No. 7, 2004, pp. 497-507. http://dx.doi.org/10.1016/j.soildyn.2004.04.002

[18] R. S. Ladd, "Preparing Test Specimen using Undercompaction," Geotechnical Testing Journal, Vol. 1, No. 1, 1978, pp. 16-23. http://dx.doi.org/10.1520/GTJ10364J

[19] M. Vucetic and R. Dobry, "Effect of Soil Plasticity in Cyclic Response," ASCE Journal of Geotechnical Engineering, Vol. 117, No. 1, 1991, pp. 89-107. http://dx.doi.org/10.1061/(ASCE)0733-9410(1991)117:1( 89)

[20] D. V. Okur and A. Ansal, "Stress-Strain Characteristics of Fine Grained Soils under Cyclic Loading," Cyclic Behaviour of Soils and Liquefaction Phenomena, Proceedings of the International Conference, Bochum, 31 March2 April 2004, pp. 179-186. 